\title{
Microbiology Specimen Method
}

National Cancer Institute

\section{Source}

National Cancer Institute. Microbiology Specimen Method. NCI Thesaurus. Code C87912.

The technique used to administer an examination of a microbiology specimen. 